TITLE: Sport Consumer Behavior Research: Improving Our Game

\author{
Daniel Funk, \\ Temple University \\ Daniel Lock \\ Bournemouth University \\ Adam Karg \\ Deakin University \\ Mark Pritchard \\ Central Washington University
}

Daniel C Funk is a Professor and Washburn Senior Research Fellow with the School of Tourism and Hospitality Management at Temple University; Daniel Lock is Senior Academic at Bournemouth University with the Department of Sport and Physical Activity, Adam Karg is a Senior Lecturer with the Department of Management at Deakin University; Mark Pritchard is a Professor at Central Washington University. Correspondence for this article should be addressed to Daniel C Funk at Temple University, 1810 N $13^{\text {th }}$ St, Speakman Hall Rm 300, Philadelphia PA, 19122 email: dfunk@ temple.edu 


\begin{abstract}
Sport consumer behavior (SCB) research continues to grow in both popularity and sophistication. A guiding principle in much of this research is that sport consumers seek out sport-related experiences, and the benefits they yield, in order to satisfy needs and wants. This approach has provided new knowledge and insight into sport consumers. One outcome of this focus is that the vast majority of research on sport consumers has centered on psychological characteristics of these sport experiences related to evaluative and affective components. In addition, this research has predominately relied on cross-sectional studies and attitudinal surveys to collect information with less emphasis on how various situational or environmental factors can influence attitudinal data patterns at the individual and group level. This special issue seeks to deepen our understanding of SCB by providing seven papers that demonstrate or validate findings using multiple studies or data collections.
\end{abstract}

Keywords: Sport Consumers, Research Methods, Sports Marketing 


\section{Sport Consumer Behavior Research: Improving Our Game}

Sport consumer behavior is a popular area of scholarship for sport management

researchers. Over the last decade, one focus for articles published in the Journal of Sport Management has been sport marketing, with the study of sport consumers in spectator sport contexts emerging as a central topic (Kim, Chelladurai \& Kim, 2015; Shilbury, 2011a). Despite sustained research interest, criticisms of this work persist due to lack of replication, failure to establish validity and reliability, misapplication of measurement instruments from other disciplines, confusion between correlation and causation, and the prevalence of single cross sectional studies (Funk, Mahony, \& Havitz, 2003). These criticisms are not unique to SCB research. However, a lack of analytical rigor, along with conceptual and operational fragmentation, can undermine the strength and clarity of work in a discipline. The cumulative effect of this can lead to a limited, narrow application of work that results in poor citations rates and narrow audiences where we speak only to ourselves instead of other disciplines (e.g., Samdahl \& Kelly, 1999), or worse yet are deemed irrelevant (e.g., Shaw, 2000).

Several assessments of impact have questioned the sports management field's over reliance on external journals and the balance between citations within and from outside the field (Shilbury, 2011a; 2011b). Although considered a malady in other fields, speaking to ourselves is not necessarily a negative for sport marketing scholars. The stated mission of the Journal of Sport Management is "to publish innovative empirical, theoretical and review articles focused on the governance, management and marketing of sport organizations" (Human Kinetics, 2016). To this end, research that focuses on and informs the sport management discipline and industry is both appropriate and required. However, elevating JSM's standing into wider academic and 
professional conversations means producing rigorous work that can inform industry

professionals and impress researchers in other academic disciplines to the point where $J S M$ articles generate regular citations in related fields, such as marketing, management, and social psychology. Some argue this endeavor may well be that the highest accolade for our research, that it is relevant and rigorous enough to be carried across-discipline (Madrigal, 1999).

Whether from triangulation of combined data approaches (Cohen \& Manion, 2000), mixed method approaches (Greene, 2007) or - as have been suggested in sport management interdisciplinary and innovative approaches (Amis \& Silk, 2005; Doherty, 2013), there is much to be gained from a focus beyond cross sectional studies. Conversely, an analysis of recent published articles reveals that the majority of SCB research relies on cross-sectional studies. A methodological assessment of 114 papers published from 2010-2014 in the Journal of Sport Management, Sport Management Review, Sport Marketing Quarterly and the European Sport Management Quarterly was conducted by the editorial team. This revealed that only $22 \%$ of published papers used multiple stages of data collection or multiple methods. Within the Journal of Sport Management for the same period, $80 \%$ of published studies used cross-sectional data collection methods. When multiple data collections were undertaken in the remaining $20 \%$, data was most likely used for scale development on the same sample or context as an antecedent to a main survey; rather than data collections actively aimed at validation over multiple contexts or regions. Overall, this assessment highlights the need for SCB research that moves beyond crosssectional study designs.

As with any academic domain, SCB research could benefit from greater attention to methodological issues. Studies that use multiple methods, studies and contexts, and employ longer observation periods can provide more robust insights into the phenomena we detect and 
strengthen the likelihood of wider cross-discipline attention. A major objective for this special issue focused on this, the goal being to generate a series of papers that use multiple studies, data sets, or data collections and encourage deeper study designs with richer forms of data that can support more rigorous testing of constructs, relationships and ideas. In the mind of the editorial team improving our game in this area means strengthening the capacity of our work to impact on the theoretical or methodological considerations of other researchers. To be relevant and citable involves intentional effort from the field but can be undertaken individually by researchers, with a view to improve per article citation rates beyond low median counts reported in the past (e.g., Kim et al., 2015).

\section{Special Issue Articles}

Within this special issue seven papers on SCB are presented. The first article titled The Development and Change of Brand Associations and Their Influence on Team Loyalty Over Time by Kunkel, Doyle, Funk, Du, and McDonald utilized an 18-month longitudinal design collecting perceptual data from sport consumers on team brand associations of a new professional football at three different time periods. The authors utilized a number of analytic techniques including Repeated Measures MANOVA, Latent Growth Modelling and CrossLagged Panel Modeling. This study provided new insight into the structure and stability of team brand associations observed in previous research (Bauer, Stokburger-Sauer, \& Exler, 2008; Gladden \& Funk, 2002). Their results revealed that team brand associations created by the team's marketing efforts before the first season were established and remained relatively stable 18 months later; despite a losing record. This finding illustrates the cognitive anchoring effect (Tversky \& Kahneman, 1974) in terms of how initial team brand associations can help determine 
and even bias subsequent judgments about the team brand. However, their results also revealed that some team brand associations were less stable than others depending upon time period observed and due to positive and negative experiences with the team. Across the three observations points, initial team brand associations were found to influence subsequent associations as well as explain team loyalty similar to previous research on existing teams (Funk \& James, 2006).

The second article entitled New Team, New Fans: A Longitudinal Examination of Team Identification as a Driver of University Identification by Katz and Heere presents a longitudinal investigation to examine how identification develops in relation to a new collegiate sport team, building on recent research in this domain (e.g., Lock, Funk, Doyle, \& McDonald, 2014). Additional to their examination of the changes to team identification, Katz and Heere also tested how changes in team identification influenced university identification. Team and university identification were measured using adapted versions of Heere and James (2007) multidimensional Team*ID scale. The analysis of longitudinal data involved a combination of latent growth curve models to explore changes in team and university identification across three studies. In this approach, the authors were able to examine the change profiles of all six dimensions of the Team*ID scale, providing a fine-grained insight into the dynamic nature of the construct and its interrelationships with university identification. Based on this longitudinal growth modelling approach, the authors' note how the creation of a new collegiate sport team achieved institutional objectives (i.e., university identification) and enabled students to feel part of a broader community through team identification.

The third article entitled 40 Years of BIRGing: New Perspectives on Cialdini's Seminal Studies ' by Jensen, Turner, Delia, Greenwell, McEvoy, Ross, Seifried and Walsh provides re- 
creations of two of Cialdini et al.'s (1976) original studies. Based on one of the most influential studies in sport consumer behavior, BIRGing theory has strongly influenced research in the field, and led to advances in both sport and non-sport settings. Heeding a lack of replication studies in consumer behavior within sport, the research provides continuing evidence of the presence of this foundation theory in sport research. The re-creation over multiple studies provides both confirmation of the existence of BIRGing and provide additional explanations and methodological extensions including advanced linguistic analysis not available to the original authors. In addition to influencing decision making and behaviors, the authors add new perspectives relevant to the impact of gender, consider BIRGing effects over time and explore the impact of past success of organizations. Four decades after the original concept was published, the paper both confirms the ongoing interest in BIRGing and raises questions to encourage continuing investigation.

The fourth article entitled No More "Good" Intentions: Purchase Behaviors in Sponsorship’ by Zaharia, Biscaia, Gray and Stotlar provides findings from a longitudinal study with a focus on understanding the factors that lead to purchase intentions in sponsorship settings. Based on theories of reasoned action and planned behaviour, it develops and tests a framework of awareness, fit, attitude toward the sponsor, past purchases and purchase intention that have been the focus of much sponsorship research to date. In a follow-up data collection, the study extends to actual purchase behaviors, thereby modelling relationships between sponsorship outcomes as antecedents to both intention and actual purchase. Evidence is provided where relationships among the analyzed sponsorship outcomes do not have a significant effect on actual purchase behaviors, concluding discordance between intentions and actual behavior in a sport sponsorship context. The focus on behavior is an important extension, given the dominant use of 
intentions as proxy measures in both sponsorship and wider academic-focused consumer

researcher. The exploration provides valid questions about how behaviors function in relation to other sponsorship outcomes.

The fifth article entitled Coping with Athlete Endorsers' Immoral Behavior: Roles of Athlete Identification and Moral Emotions on Moral Reasoning Strategies by Kwak, Lee and Braunstein-Minkove explores complex consumer processes in reaction to athlete endorsers who undertake immoral behavior. Social identification and moral psychology theories are expanded to examine emotions, morals and processes sport consumers' progress through when athletes transgress. The paper focuses on reactions to a single, high profile case with data collected from two separate studies. Findings show highly identified fans regulate negative emotions but select specific moral reasoning strategies to maintain their positive stance toward the athlete. New insights contributing to the SCB literature demonstrate how sport consumers advance through emotional and cognitive processes to arrive at moral judgments regarding athlete transgressions. Specifically, it demonstrates the direct role of fan identification in motivating sport consumer response and role of negative emotions in consumer selection and activation of moral reasoning strategies.

The sixth article entitled Determinants of Word-of-Mouth Influence in Sports Viewership by Ko and Asada presents a two study quantitative methodology exploring how certain characteristics of word-of-mouth communication influence sport viewership behavior. In their first study, Ko and Asada conducted a pilot test, which examined the structure of the measurement items planned for use in their main study. In study 2 , the authors began by conducting a test for configural invariance to ascertain whether the model structure observed in studies one and two were equivalent (e.g., Horn \& McArdle, 1992). From this robust basis, the 
authors found that trustworthiness, richness, and strength of message delivery had a positive and significant effect on word-of-mouth influence. Further analysis demonstrated that homophily (similarity with the communication source) moderated the relationship between expertise and word of mouth influence. In addition, involvement moderated the paths between richness of message content and strength of message delivery. Together, this paper provides a rigorous insight into the factors under pinning a word-of-mouth source that influences sport consumer behavior.

The seventh and final article entitled Consumer Interest in Major League Baseball: An Analytical Modeling of Twitter by Wanatabe, Yan and Soebbing, seeks to understand the determinants of sport consumers' interest in social media (Twitter) accounts of an MLB team. To do this the authors utilize data scraping software that collects one year of data on MLB team Twitter followers, as well as followers of each team's starters. The work then employs regression modelling with two unique features. First, it considers two dependent variables, total Twitter followers for each MLB team per month for a year and changes in Twitter followers for MLB team accounts per month. Second, the research uses a variety of independent variables, including the contribution of followers of individual athletes, to examine consumer interest in social media accounts of teams. This type of inquiry is viewed by the editors as both interesting to the field given the widespread usage of social media by businesses and consumers alike, and relevant to the special issue call for research that "identifies and validates data patterns with multiple methods or samples." 


\section{Conclusion}

This special issue presents seven articles highlighting research in sport consumer behavior. The articles represent a continued interest by academics in sport management to better understand sport consumers. The articles in this issue make a contribution through the use of multiple or mixed method studies, multiple samples and longer observation periods aligned with techniques to increase depth, generalizability, and an increased ability to triangulate findings. Given the response of authors and the caliber of papers that resulted from the call, we encourage a continued emphasis on rigorous work. This special issue will hopefully provide a benchmark for "improving our game" and add further value to the interpretation and generalizability of sport marketing research. 


\section{References}

Amis, J., \& Silk, J. (2005). Rupture: Promoting critical and innovative approaches to the study of sport management. Journal of Sport Management, 19, 355-366.

Bauer, H. H., Stokburger-Sauer, N. E., \& Exler, S. (2008). Brand image and fan loyalty in professional team sport: A refined model and empirical assessment. Journal of Sport Management, 22, 205-226.

Cohen, L., \& Manion, L. (2000). Research methods in education, 5th ed. London: Routledge.

Cialdini, R.B., Borden, R.J., Thorne, A., Walker, M.R., Freeman, S., \& Sloan, L.R. (1976). Basking in reflected glory: Three (football) field studies. Journal of Personality and Social Psychology, 31, 366-375.

Doherty, A. (2013). It Takes a Village:" Interdisciplinary Research for Sport Management. Journal of Sport Management, 21, 1-10.

Funk, D. C. \& James, J. D. (2006). Consumer loyalty: The meaning of attachment in the development of sport team allegiance. Journal of Sport Management, 20, 189-217.

Funk, D.C., Mahony, D.F., \& Havitz, M. (2003). Sport consumer behavior: Assessment and direction. Sport Marketing Quarterly, 12, 200-205.

Gladden, J.M., \& Funk, D.C. (2002). Developing and understanding of brand association in team sport: Empirical evidence from professional sport consumers. Journal of Sport Management, 16, 54-81.

Greene, J. C. (2007). Mixed methods in social inquiry. San Francisco, CA: Jossey-Bass.

Heere, B., \& James, J.D. (2007). Stepping outside the lines: Developing a multi-dimensional team identity scale based on social identity theory. Sport Management Review, 10, 65-91.

Horn, J.L. \& McArdle, J.J. (1992). A practical and theoretical guide to measurement invariance in aging research. Experimental Aging Research, 18, (3-4), 117-144.

Human Kinetics (2016). Journal of sport management mission statement. Retrieved from http://journals.humankinetics.com/jsm-mission

Kim, A.C.H., Chelladuria, P., \& Kim, Y.K. (2015). Scholarly trusts in the Journal of Sport Management: Citation Analysis. Global Sport Management Journal, 3, 1-20.

Lock, D., Funk, D. C., Doyle, J. P., \& McDonald, H. (2014). Examining the longitudinal structure, stability, and dimensional interrelationships of team identification. Journal of Sport Management, 28, 119-135. 
Madrigal, R. (1999). Comment on the impact of leisure research. Journal of Leisure Research, 31(2), 195-198.

Samdahl, D. M., \& Kelly, J. J. (1999). Speaking Only to Ourselves? Citation Analysis of 'Journal of Leisure Research' and 'Leisure Sciences'. Journal of Leisure Research, 31, 171.

Shaw, S. (2000). If our research is relevant, Why is nobody listening? Journal of Leisure Research, 32, 147-151.

Shilbury, D. (2011a). A bibliometric study of citations to sport management and marketing journals. Journal of Sport Management, 25, 423-444.

Shilbury, D. (2011b). A bibliometric analysis of four sport management journals. Sport Management Review, 14, 434-452.

Tversky, A., \& Kahneman, D. (1974). Judgment under uncertainty: Heuristics and biases. Science, New Series, 185, 1124-1131. 